\title{
Twenty years of vocational training in the west of Scotland
}

\author{
Diane R Kelly, T S Murray
}

\begin{abstract}
Objective-To assess the career paths of doctors who completed vocational training in the west of Scotland between 1968 and 1987 and their views on the hospital component of their training.

Design-Retrospective analysis of the experience and opinions of vocationally trained doctors obtained from a postal questionnaire.

Setting - West of Scotland.

Subjects-1255 Doctors identified from Glasgow University records who had been vocationally trained in the west of Scotland between 1968 and 1987.

Main outcome measures-Personal details; employment; jobs held currently; additional professional commitments; importance of hospital posts held in various specialties to respondents currently in general practice; and retrospective choice of hospital posts, based on subsequent experience.
\end{abstract}

Results-619 Responses were received, 543 initially and 76 after a letter of reminder, from a possible total of 974 (excluding 153 questionnaires returned by the post office and 128 returned because of misunderstanding between the name and address); the overall response rate was therefore $64 \%$. 607/619 $(98 \%)$ Respondents were employed at the time of the study, of whom $517 / 607(85 \%)$ were in general practice. A third $(202 / 609)$ had been unemployed at some point, significantly more of them women $(122 / 243,50 \% v$ $80 / 376,21 \%$; $\left.\chi^{2}=54.8, p<0.001\right) .510 / 563(91 \%)$ Respondents held one postgraduate qualification or more, and $284 / 612(46 \%)$ had additional professional commitments. The hospital posts most commonly held were in obstetrics and gynaecology, psychiatry, paediatrics, and medicine. Medicine, obstetrics, paediatrics, and dermatology were considered to be the most relevant hospital specialties by those who had experience of them and were now in general practice. Although ophthalmology and ear, nose, and throat were not rated highly by these doctors, other respondents wished that they had held posts in these specialties ( 32 and 40 respectively). During the hospital training $354 / 475(75 \%)$ respondents thought that they were looked on as a junior hospital doctor and not as a trainee for general practice.

Conclusions-Most of those who had entered vocational training were in employment, and most were in general practice. According to them, the most beneficial hospital posts for vocational training are medicine, obstetrics, paediatrics, and dermatology. Trainees should be encouraged to attend clinics in gynaecology, ear, nose, and throat, and ophthalmology.

\section{Introduction}

Vocational training for general practice has been established in the west of Scotland since 1968, although official legislation did not exist until $1979 .{ }^{12}$ The aim of this study was to question doctors who had completed vocational training since 1968 , to trace their career paths, and to ascertain their views on their vocational training and any suggestions for alterations or improvements. There are 16 formal training schemes in the west of Scotland. Most consist of two years in hospital posts and one year in general practice. Two schemes, however, consist of 18 months in hospital posts and 18 months in general practice; another scheme consists of two years in hospital posts with the practice year divided into two periods of six months in the same practice, at the beginning and end of the scheme.

\section{Subjects and methods}

A questionnaire including 57 stem questions was designed. It comprised four sections: personal details, hospital component, practice component, and details of training practice. A pilot study of its use was carried out on a group of 10 general practitioners. After modification based on their comments the questionnaire was posted in March and April 1989 to 1255 doctors identified by examining lists of trainees from 1968 to 1987 from the university's department of postgraduate medicine and matching their names with current addresses in the Medical Directory. The maximum number of doctors that could be so identified was 1255 . Four weeks after the initial posting a reminder letter was sent to those who had not responded. Respondents were identified by a number on the first page of the questionnaire, which was included for that purpose alone; their names did not appear on the questionnaire. The replies were analysed with an Amstrad computer using Minitab data analysis software, version 6.1.

\section{Results}

A total of 619 responses were received, 543 initially and a further 76 after the reminder letter; 153 were returned by the post office as the doctor was no longer known at that address; and a further 128 were returned as we had incorrectly matched the name with the address, and the questionnaire had been sent to the wrong person. The overall response rate was therefore $64 \%(619 / 974)$.

\section{CHARACTERISTICS OF RESPONDENTS}

Of the 619 respondents, 243 (39\%) were women and $376(61 \%)$ were men. Their ages ranged from 26 to 56 (mean 34). Most $(502,81 \%)$ were married, 101 $(16 \%)$ were single, eight $(1 \%)$ divorced, and three $(<1 \%)$ widowed. Their dates of graduation ranged from 1956 to 1984 . Scotland was the place of graduation for 530 of 612 respondents $(87 \%)$, England and Wales for $45(7 \%)$, Ireland for $19(3 \%)$, and abroad for 18 (3\%). The number of postgraduate qualifications held by those questioned ranged from zero to six (median two) and were as follows ( $n=619$ respondents): MRCGP, 364; DRCOG, 355; DCH, 69; family planning, 60; MRCP, 36; DA, 17; MRC, 8; MSC, 4; and MRCOG, 3. Fifty 
TABLE I-Range of jobs held by 90 respondents not in general practice subsequent to training. (Response to questions Are you working at present? If so what are you doing?)

\begin{tabular}{lr}
\hline Current job & No \\
\hline Clinical medical officer in & \\
paediatrics & 12 \\
Anaesthetics & 9 \\
Psychiatry & 8 \\
Clinical medical officer & 6 \\
Research & 6 \\
Obstetrics and gynaecology & 5 \\
Forces & 5 \\
Dermatology & 4 \\
Accident and emergency & \\
medicine & 2 \\
Paediatrics & 4 \\
Geriatrics & 3 \\
Community health & 3 \\
Occupational medicine & 3 \\
Primary health lecturer & 3 \\
Family planning/well woman & \\
medicine & 2 \\
General practice/anaesthetist & 2 \\
Radiology & 2 \\
Kenya community health & 2 \\
Infectious diseases & 2 \\
Medicine & 2 \\
Student health service & 1 \\
Child psychiatry & 1 \\
Mental handicap & 1 \\
Surgery & 1 \\
Director of public health & 1 \\
\hline
\end{tabular}

Director of public health six per cent $(338 / 603)$ had been on self constructed schemes, $42 \%(254 / 603)$ on formal schemes, and $2 \%$ $(11 / 603)$ on a combination of both.

\section{CAREER PATH}

Of the 619 respondents, 607 (98\%) were in employment; only 11 were not working and in only one case was this involuntary (one respondent did not answer this question). Of those employed 517 of 607 $(85 \%)$ were working in general practice, and within that group $487(96 \%)$ were principals and $218(43 \%)$ were in a training practice. Table I shows the range of jobs held by those not in general practice.

Unemployment had been experienced at some point by 202 of 609 doctors (33\%), significantly more of them women $\left(122 / 243,50 \% v 80 / 376,21 \% ; \chi^{2}=54 \cdot 8\right.$, $\mathrm{p}<0.001)$. The reasons respondents gave for a period of unemployment were as follows (some gave more than one answer): maternity and family commitments (74 respondents), no available job (51), awaiting a job starting (24), travel or holiday (28), and moving house (14).

The number of jobs respondents had held after completing their vocational training ranged from one to 16 . Those with only one job amounted to $331 / 604$ (55\%), those with two jobs 149 (25\%), and those with three jobs or more 124 (21\%). Just over half $(345 / 619$, $56 \%$ ) had experience of locum work. Time spent as a locum ranged from one session to seven years (median two months). Additional professional commitments were held by $284 / 612(46 \%)$ respondents (table II).

TABLE II-Additional professional commitments of 284 respondents. (Response to question Do you have any other professional commitments - for example, other jobs, membership of committee?)

\begin{tabular}{lc}
\hline Commitment & No \\
\hline Clinical assistant & 68 \\
Committee member & 67 \\
Local medical committee member & 45 \\
Occupational medicine & 27 \\
Family planning & 23 \\
Hospital medical officer & 17 \\
Clinical medical officer & 16 \\
Doctors' deputising service & 14 \\
Department of Health and Social Security post & 13 \\
Police surgeon & 12 \\
Research & 7 \\
Lecturer & 6 \\
Scottish GMSC & 5 \\
Women's Federation member & 3 \\
Sports medicine & 3 \\
\hline
\end{tabular}

THE HOSPITAL COMPONENT OF VOCATIONAL TRAINING

The vocational training of the 619 respondents began between 1967 and 1987. The number of postregistration hospital posts they held ranged from one to 10 . None had no postregistration experience in hospital, 11 had one job (2\%), 29 had two jobs $(5 \%), 91$ had three (15\%), 317 had four (53\%), 100 had five $(16 \%), 34$ had six $(6 \%)$, two had eight $(1 \%)$, and three had $10(1 \%)$. Table III shows the hospital jobs performed and table IV those jobs considered to have been most relevant by respondents now in general practice. In retrospect $41 \%(246 / 600)$ replied that they wished they had chosen a different set of hospital posts, and table $V$ shows these.

In 1982 it became a legal requirement that three years should be spent in vocational training, during which there should be experience of six months in two hospital specialties. ${ }^{3}$ In this study $456 / 595(77 \%)$ respondents spent two years or more in hospital training. Of those who trained before 1982, 283/336 $(84 \%)$ thought the length of time they had spent in hospital was about correct, 19/336 (6\%) that it was too long, and $26 / 336(8 \%)$ that it was too short; and $8 / 336$ (2\%) were uncertain. After 1982 the figures are not dissimilar; $181 / 218(83 \%)$ considered the time correct,
TABLE III-Postregistration hospital posts held by 600 respondents, 1967-87. (Response to statement Please outline hospital posts)

\begin{tabular}{lc}
\hline Post & No \\
\hline Obstetrics and gynaecology & 356 \\
Psychiatry & 323 \\
Paediatrics & 315 \\
Medicine & 274 \\
Accident and emergency medicine & 223 \\
Geriatrics & 195 \\
Obstetrics & 188 \\
Infectious diseases & 69 \\
Dermatology & 64 \\
Accident and emergency medicine/orthopaedics & 53 \\
Gynaecology & 37 \\
Ear, nose, and throat & 33 \\
Respiratory medicine/anaesthetics & 30 \\
Medicine/geriatrics & 27 \\
Orthopaedics & 20 \\
Surgery & 19 \\
Community medicine & 13 \\
Paediatric surgery & 8 \\
Cardiology & 7 \\
Rheumatology & 6 \\
Haematology and community paediatrics & 5 \\
Ophthalmology & 3 \\
Homoeopathy & 2 \\
\hline
\end{tabular}

TABLE IV - Hospital posts considered most necessary by 517 respondents currently in general practice. (Response to question Which post $(s)$ do you feel are most necessary to you now in your current job?)

\begin{tabular}{lc}
\hline Post & $\mathrm{No}^{\star}(\%)$ \\
\hline Medicine & $162 / 225(72)$ \\
Obstetrics & $109 / 152(72)$ \\
Paediatrics & $181 / 259(70)$ \\
Dermatology & $33 / 48(69)$ \\
Accident and emergency medicine & $102 / 173(59)$ \\
Psychiatry & $150 / 259(58)$ \\
Gynaecology & $15 / 27(56)$ \\
Obstetrics and gynaecology & $150 / 288(52)$ \\
Geriatrics & $73 / 155(47)$ \\
Infectious diseases & $24 / 55(44)$ \\
Ear, nose, and throat & $9 / 25(36)$ \\
\end{tabular}

$\star$ Denominator refers to number of respondents who had held posts in the specialty who replied.

TABLE V-Hospital posts 246 respondents now wish they had chosen. (Response to question Would you now choose a different post? Please state which)

\begin{tabular}{lc}
\hline Post & No \\
\hline Paediatrics & 67 \\
Dermatology & 52 \\
Medicine & 46 \\
Psychiatry & 43 \\
Ear, nose, and throat & 40 \\
Ophthalmology & 32 \\
Accident and emergency medicine & 16 \\
Obstetrics and gynaecology & 15 \\
Gynaecology & 13 \\
Geriatrics & 12 \\
Obstetrics & 4 \\
\hline
\end{tabular}

$13 / 218(6 \%)$ considered it too long, and $22 / 218(10 \%)$ considered it too short and $2 / 218(1 \%)$ were uncertain. It did not seem that before 1982 less time was spent in hospital training because $252 / 343(74 \%)$ of those training at that time had had four hospital posts or more

Of the respondents, $354 / 475(74 \cdot 5 \%)$ perceived that they were regarded by most of their senior hospital colleagues as junior hospital doctors and not as a trainee for general practice.

\section{Discussion}

Since 1979 a one year traineeship has been a legal requirement for general practice. ${ }^{12}$ In 1982 a period of six months spent in two hospital specialties after registration also became compulsory. ${ }^{3}$ It has been unusual to obtain the opinions of trainees in the past ${ }^{4-15}$; any studies performed usually involved only small numbers of trainees. This study concerns a large number of trainees over an extended time scale. 
There were notably more men than women in the study. In the current intake of medical students a Glasgow University the sex ratio is about $1: 1$ and has been so since 1979. In this study, however, some respondents started medical school before this time, with a small number graduating in the early 1950 s. Most were married; interestingly, however, only $1 \%$ were divorced, which is well below the current rate for Scotland of 1 in $4 .{ }^{16}$ Only 9\% (53/563) of the respondents had no postgraduate qualifications. If the 9\% (56/619) who failed to answer this question are considered this may raise the final figure as some may have omitted this question because they had no qualifications. The maximum, however, could only be $18 \%$, which is still lower than we would have expected given the time scale of the study.

Encouragingly, 98\% (607/619) of the respondents were employed, and unemployment, although covered frequently in the popular press, did not seem to be a problem; repeating the study after implementation of the government's new contract ${ }^{17} 18$ might be revealing. Over $80 \%(507 / 607)$ of respondents were working in general practice, and the remainder were in a wide variety of jobs. Although almost all respondents were employed, 33\% (202/607) had experienced unemployment at some time, notably women. The commonest reason given was family commitment, which was also found by Parkhouse. ${ }^{8}$ Interestingly, $43 \%$ of those in general practice were in a training practice as in the west of Scotland $30 \%$ of practices are training practices. This may be explained by the fact that some people were in fact currently working outwith the west of Scotland and also that general practitioners working in a training practice may be more likely to have responded to this type of questionnaire as they may have thought that it was more relevant to them.

Forty five percent of respondents (273/604) had held more than one job since completing their training, but there was no trend over the time of the study. Whether the jobs were in general practice was not, however, established, but ex-trainees who completed their training more recently may be more mobile than their predecessors as they have effectively had more than one job over a shorter period and this may merit further study.

The most popular hospital posts held by respondents after registration were obstetrics and gynaecology, psychiatry, paediatrics, and medicine, as also shown by Styles ${ }^{4}$ Short ${ }^{5}$ and Thornham. ${ }^{6}$ The posts considered most relevant by respondents now in general practice were medicine and obstetrics. ${ }^{7}$ Only 45\% (271/600) of respondents, however, had actually held a post in medicine, which gives cause for concern. Of those $271,164(61 \%)$ had been in a formal scheme and only $97(36 \%)$ in a self constructed scheme $\left(\chi^{2}=77.65\right.$, $\mathrm{p}<0.001)$. This may therefore be a problem for, although many formal schemes include a medical job (13 out of 18 in the west of Scotland), doctors in self constructed schemes may have difficulty obtaining such a post. Equal numbers of respondents who had held a post in obstetrics and gynaecology had been in formal and self constructed schemes, and among those who had held an obstetric post alone, more had been on self constructed schemes. This is surprising as obstetric posts are popularly believed to be difficult to obtain in self constructed schemes.

Geriatrics and medicine were not considered of equal relevance by respondents in this study (table IV); geriatrics was rated as relevant by only $47 \%(73 / 155)$ of respondents who had held posts in the specialty compared with $72 \%(162 / 225)$ of those who had held posts in medicine. Gynaecology was not rated as particularly useful, as reported previously, ${ }^{7}$ which is perhaps surprising as gynaecology is an important component of general practice. The balance of teaching, however, may be incorrect-for example, time being spent in theatre as a gynaecology resident when perhaps attendance in an outpatient clinic may be more relevant. Paediatrics was rated second with regard to relevance. It is therefore worrying that $48 \%(286 / 601)$ of respondents had no paediatric experience. Of those with experience, $62 \%(195 / 315)$ had been in self constructed schemes; therefore it seems that more formal schemes should include paediatrics. Surprisingly, dermatology was rated as the third most relevant hospital job. Only $11 \%(64 / 600)$ of the respondents, however, had actually worked in dermatology. In view of its high rating perhaps dermatology should be included in many more training schemes. Ophthalmology and ear, nose, and throat were not rated highly. However, 40 respondents wished that they had held ear, nose, and throat hospital posts and 32 that they had had ophthalmology posts. Trainees should perhaps be encouraged to attend more outpatient clinics in these specialties as they may gain more valuable experience this way.

Two years seems to be a reasonable period to spend in hospital training. This study shows that there is still a problem in trainees being recognised as trainees for general practice rather than as junior hospital doctors and therefore being trained appropriately. ${ }^{14}$ If this attitude were improved and the balance corrected many of the hospital posts might become more relevant to general practice.

We thank all those from the university departments of general practice in Glasgow and Edinburgh for their valued help and advice; Irene Lynch for her invaluable clerical help, and Harper Gilmour, department of public health, Glasgow University, for his statistical advice.

1 National Health Service (Vocational Training) Act 1976. London: HMSO, 1976. (76 C.59.)

2 National Health Service (Vocational Training) Regulations 1979. London: HMSO, 1979.

3 1980/30 National Health Service (Vocational Training) (Scotland) Regulations 1980. London: HMSO, 1980. (Statutory instrument.)

4 Styles WMcN. Vocational training for general practice-hospital experience. London: Sabercrown Publishing, 1989;399:158-9.

5 Short NL. Vocational training for general practice in Dartford 1971-1982: an assessment. Med Teach 1987;9:193-9.

6 Thornham JR. A survey of ex-trainees. F R Coll Gen Pract 1980;221:725-8.

7 Martys CR. Some trainees' views on vocational training. Update 1979;18: 1079-81.

8 Parkhouse J. Career paths in general practice. Update 1989;38:924-6.

9 Gray DJP. The history of vocational training. In: Training for general practice. Plymouth: MacDonald and Evans, 1982:1-17.

10 Freer $\mathrm{CB}$, Reid ME. A survey of past trainees. Vocational training forum. Update 1978;16:1461-8.

11 Donald JB. The trainee year-a critical appraisal. BMf 1975;i:672-5.

12 Whitfield MJ. Training for general practice: result of a survey into the general practitioner trainee scheme. BMJ 1966;i:663-7.

13 Reeve $\mathrm{H}$, Bowman A. Hospital training for general practice: views of trainees in the NW region. BMf 1989;298:1432-4.

14 Crawley HS, Levin JB. Training for general practice: a national survey. $B M \mathcal{F}$ 1990;300:911-5.

15 Ronalds C, Douglas A, Gray DJP, Selley P, eds. Fourth national trainee conference report, recommendations, and questionnaire Exeter, 1980 . London: Royal College of General Practitioners, 1981. (Occasional paper 18.)

16 Registrar General. Registrar General Scotland annual report 1985. Edinburgh: HMSO, 1985:118-24.

17 Department of Health. Terms of service for doctors in general practice. London: DoH, 1989.

18 General Medical Services Committee. NHS regulations: the National Health Service (general medical and pharmaceutical services) regulations, October 1989. London: GMSC, 1989.

(Accepted 5 October 1990) 